\title{
Candida Infections: Clinical Features, Diagnosis and Treatment
}

\author{
S.P. Bouopda Tamo \\ Department of Biochemistry, University of Yaounde I, Yaounde, Cameroon
}

\begin{abstract}
Candidiasis is an opportunistic infection caused by yeasts of the genus Candida. In recent years, there has been a great deal of interest in Candida infections because of the resurgence of diseases that weaken the immune system and the widespread use of immunosuppressive chemotherapy. The choice of diagnosis method and identification of the Candida species at the origin of the infection is essential for better management of patients, because the infectious mechanisms and the sensitivity to antifungal agents can vary from one Candida species to another. This review provides an overview of the Candida species involved, clinical aspects, diagnostic methods, and treatments available against candidiasis encountered in human pathology.
\end{abstract}

Keywords: Candidiasis, clinical aspects, diagnosis, treatments

\section{INTRODUCTION}

E ach year, fungal infections affect more than one billion people worldwide, with more than 1.6 million deaths $(1,2)$. Candidiasis accounts for 75 to $88 \%$ of these infections, and despite therapeutic advances, their incidence continues to increase with increasing mortality. The clinical spectrum of candidiasis extends from superficial diseases such as cutaneous, nail, digestive, and genital candidiasis, to systemic diseases such as candidemia $(3,4)$. Yeasts of the genus Candida cause these infections. Over 200 species of Candida have been listed, and only around 20 are responsible for human infections. These are generally commensal germs that develop in the skin, inside the body, in the mouth, throat, intestines, vagina, without causing problems (5). They express their pathogenic power only in the presence of factors favoring the origin of the translation of endogenous commensal to the disease-causing parasite. These factors can be intrinsic or extrinsic to the host, and we distinguish the medical condition of the host for overweight, prolonged use of broad-spectrum antibiotic therapy and corticosteroids, etc. $(6,7,8)$. Immunosuppression remains one of the most prevalent risk factors (9). The resurgence of diseases weakening the immune system, such as AIDS, and immunosuppressive treatments, such as heavy chemotherapy, has led to a drastic increase in Candida infections, which have become a major cause of mortal-
Corresponding Author: S.P. Bouopda Tamo

E-mail: sylvainbouopda@gmail.com

Received: April 19, 2020 Accepted: July 28, 2020 Published: August 31, 2020

Suggested citation: Bouopda Tamo SP. Candida Infections: Clinical Features, Diagnosis and Treatment. Infect Dis Clin Microbiol 2020; 2: 91-102.

DOI: $10.36519 / \mathrm{idcm} .2020 .0006$ 
ity and morbidity in hospitals. The disseminated forms of the candidiasis can be life-threatening with mortality rates of $35-60 \%$ among immunocompromised cancer patients, and those exposed to multiple treatments, such as broad-spectrum antibiotics, chemotherapy, immunosuppressive therapy, and antiretroviral therapy $(10,11)$. On the other hand, inappropriate medical practices such as misdiagnosis and inadequate medication are responsible for the worsening, spread, and persistence of the infection.

Several approaches allowing the efficient diagnosis of Candida infections are being used today. Conventional techniques are mainly based on recognizing symptoms, direct collection and examination of clinical samples, culture and identification of the morphological, biochemical, immunological or molecular characteristics of the Candida species at the origin of the infection. Candida's infectious strains differ widely, both in their ability to cause infection and their susceptibility to antifungal agents (12, 13). The correct identification of Candida species is of great importance, as it presents prognostic and therapeutical significance, allowing an early and appropriate antifungal therapy $(14,15)$. The sensitivity of Candida species to antifungal agents can vary from one phenotype to another. The therapeutic arsenal used in the treatment of candidiasis remains limited and is subject to many difficulties,

\section{HIGHLIGHTS}

- Candidiasis represents about $80 \%$ of fungal infections and its prevalence is increasing due to the resurgence of diseases that weaken the immune system and the more widespread use of immunosuppressive chemotherapy.

- For better patient management, the choice of the diagnosis method and the identification of the Candida species that is responsible for the infection are essential, because the infectious mechanisms and the sensitivity to antifungal agents can vary from one species to another.

- The fight against candidiasis is based on the adoption of measures to prevent the spread of infection and the use of antifungals. including the emergence of microbial multidrug resistance $(16,17)$. The diagnosis and identification of the Candida species at the origin of the infection and the determination of its sensitivity profile to available antifungal agents are therefore essential for effective treatment.

This review provides an overview of the germs involved in Candida infections, clinical aspects, diagnosis methods, and treatments.

\section{Candida yeasts}

Candida is opportunistic eukaryotic cosmopolitan yeasts belonging to the Ascomycota phylum, the Hemiascomycetes class, the Saccharomycetales order, and the Candidaceae family. These are non-pigmented, non-encapsulated, aerobic or facultative anaerobic and single-cell thallus organisms which reproduce asexually by budding spores (18). They vary in size (3 to $15 \mu \mathrm{m}$ ) and are distinguished from other yeasts by the polysaccharide composition of their cell wall and their ability to present different morphologies. Depending on the environmental conditions ( $\mathrm{pH}$, temperature, etc.), they can take a more elongated and cylindrical shape, called pseudomycelium or mycelium (19). Pseudomycelium development is due to a lack of detachment of the bud from the mother cell. That of the germ tube and true mycelium, on the other hand, is species-dependent and observed only for Candida albicans and Candida dubliniensis. Candida is heterotrophic microorganisms that only develop in the presence of organic matter. These are endogenous or exogenous commensal germs that express their pathogenic power in the presence of promoting factors. They are responsible for more than $80 \%$ of yeast infections in humans (20).

\section{The main Candida species involved in human pathology}

The genus Candida includes more than 200 species, of which only around twenty are responsible for pathological manifestations in humans (21). Table 1 below presents some Candida species commonly isolated in clinical settings and their ecology.

\section{Virulence factors}

In general, a combination of factors related to the host's immunological and physiological status and 
the yeast itself favor Candida infections. Most often, a reduction in host defenses changes the balance of commensalism in favor of yeast and leads to the switch from colonization to infection. The virulence factors contributing to the installation of Candida, its maintenance and its proliferation in the host can be adhesion of the pathogen to tissues, dimorphism, the formation of biofilms, secretion of enzymes, regulation of the surrounding $\mathrm{pH}$, metabolic adaptation and interference with the immune system (23).

\section{Clinical aspects}

Candidiasis is an opportunistic infection caused by yeasts of the genus Candida. They represent more than $80 \%$ of yeast infections, and their frequency has increased exponentially in recent years (24). Depending on the site of infection, candidiasis can be superficial or systemic (22).

\section{Superficial candidiasis}

The adhesion of Candida to epithelial cells, its multiplication, and filamentation capacity are at the origin of inflammatory lesions called superficial candidiasis. Superficial candidiasis is the most common clinical form of Candida infection. They can occur in both healthy and immunocompromised individuals. Depending on the site reached, a distinction is made between mucosal candidiasis, cutaneous candidiasis, and nail candidiasis $(25,26)$.

\section{Mucosal candidiasis}

Mucosal candidiasis is extremely common and vastly more common than invasive, systemic candidiasis, although the latter receives far more attention due to the accompanying mortality. The mucosal surfaces affected by candidiasis can be the oral mucosa, pharynx, esophagus, intestines, urinary system, and vaginal mucosa. Candida infections of the mucous membranes are oropharyngeal, esophageal, and urogenital candidiasis $(25,26)$.

Oropharyngeal candidiasis: It is also called oral candidiasis, oral thrush, moniliasis, Candidal stomatitis, or muguet. Oropharyngeal candidiasis manifests as creamy white lesions, usually on the tongue or inner cheeks. Sometimes it may spread to the roof of the mouth, gums or tonsils, or the back of the throat. Candida albicans is the most commonly im-
Table 1. Candida species commonly isolated in clinical settings and their ecology (22)

\begin{tabular}{|l|l|}
\hline Most frequent species & Ecology \\
\hline C. albicans & $\begin{array}{l}\text { Commensal yeast from the digestive, genital } \\
\text { and respiratory tract mucosa, represents } \\
\text { more than 75\% of yeasts isolated in humans }\end{array}$ \\
\hline C. glabrata & Digestive mucosa and urogenital tract \\
\hline C. parapsilosis & Skin \\
\hline C. tropicalis & $\begin{array}{l}\text { Soil, water, digestive tract, urinary and } \\
\text { respiratory tract }\end{array}$ \\
\hline C. krusei & Food (Dairy, Beer) \\
\hline Less common species & Ecology \\
\hline C. dubliniensis & Birds, digestive tract \\
\hline C. guilliermondii & Skin \\
\hline C. lusitaniae & Environment, digestive tract of animals \\
\hline C. kefyr & $\begin{array}{l}\text { Food, digestive tract, respiratory and urinary } \\
\text { tract }\end{array}$ \\
\hline C. lipolytica & Animals and plants \\
\hline C. ciferrii & Onychomycosis \\
\hline C. inconspicua & Digestive tract, hospital environment \\
\hline C. rugosa & Water, Food (dairy products) \\
\hline C. famata & Skin \\
\hline C. africana & Vagina \\
\hline & \\
\hline
\end{tabular}

plicated organism in this condition. The prevalence of oropharyngeal candidiasis remains very high in immunocompromised patients, and three clinical forms are generally encountered among which pseudomembranous, atrophic erythematosus, and hyperplastic candidiasis (27).

Esophageal candidiasis: It is also known as candidal esophagitis or monilial esophagitis. It is the most common type of infectious esophagitis and manifests as inflammatory plaques in the esophagus, which cause painful dysphagia, heartburn, and back pain. In the immunocompromised, lesions may spread in the stomach and small intestine (28). There are about 20 species of Candida that can cause the condition, but Candida albicans usually cause it. 
Urogenital Candidiasis: Candida albicans is the main cause of genital candidiasis. The infection, which most often occurs endogenously, is linked to the development of the germ already present in the genital organ or on the skin $(17,18)$. We distinguish:

Candida vulvovaginitis: It is a widespread vaginal infection that is seen, especially in pregnant women, women with an intrauterine device or taking oral contraceptives. It is characterized by erythematous and edematous lesions, vaginal discharge (leukorrhea) with lumps, and itchy vulva (28).

Candida balanitis: This is an inflammation of the tip of the penis that begins at the balano-prepucial fold, and then spreads to the glans and foreskin. It is characterized by the formation of erythematous plaques of a reddish color, which causes itching and more or less intense irritation. It is generally due to a lack of hygiene (29).

Candida cystitis: It is a lesion localized in the pelvis. It is accompanied by the formation of a fungal ball, an inflammation of the urinary meatus, and urethritis (17). In most cases, Candida cystitis is associated with a urinary catheter.

\section{Cutaneous and nail candidiasis}

Among these infections, one distinguishes chronic mucocutaneous candidiasis, intertrigo, and onychomycosis $(30,31)$.

Chronic mucocutaneous candidiasis: This is a genetic condition that mainly affects people with an impaired immune response. It is characterized by chronic inflammation in the skin, hair, face, scalp, and hands. This infection is associated with a defect in cell-mediated immunity that may be limited to Candida antigens or be part of a more general immune abnormality. Recent data suggest alterations in cytokine production in response to Candida antigens. These alterations include decreased IL-2 and $\gamma$-IFN levels and increased IL-10 levels in some studies (30).

Intertrigo: It is a widespread inflammation affecting skin-on-skin contact, such as the groin, armpits, under the breasts, and skin folds on the anterior torso (panniculus). The main factor in the lesions' development is the mechanical friction on the skin that initially appears as minimal erythema of the folds. Lesions mostly develop in the neck, axilla, sub-mammary fold, and perineum, while other sites may also be involved, including antecubital, umbilical, perianal, and interdigital areas as well as abdominal folds, eyelids, and the retroauricular area. Intertrigo can be complicated by various microorganisms, including candida yeasts and favored by obesity, humidity, and maceration, as well as lack of hygiene (31).

Onychomycosis: Also known as tinea unguium, onychomycosis is a fungal infection of the nail. Candida species invade nails previously damaged by infection or trauma. Symptoms include white or yellow nail discoloration, thickening of the nail, and separation of the nail from the nail bed. Onychomycosis occurs primarily in adults, most commonly after 60 years of age. Patients with chronic mucocutaneous candidiasis may also develop a candidal infection of the nails (32).

\section{Systemic candidiasis}

Systemic candidiasis is the most severe manifestation of Candida infection. They can be the consequence of exogenous contamination (perfusion, surgical intervention, etc.) or be consecutive to the passage to the blood and deep organs of yeasts that have colonized digestive or genitourinary sites (33). Systemic candidiasis corresponds to Candida septicemia (candidemia) or a deep candidal focus (visceral lesions). Yeasts spread through the bloodstream to various organs of the body, adhere to tissues, filament and can lead to severe conditions such as encephalitis. The organs most often affected are the heart, the kidneys, the liver, and the eye. The mortality rate from systemic candidiasis is around $50 \%$. These infections are in $95 \%$ of cases caused by the species Candida albicans, Candida glabrata, Candida parapsilosis, Candida tropicalis, and Candida krusei $(34,35)$.

\section{Factors favoring candidiasis}

The factors favoring candidiasis can be intrinsic or extrinsic to the host (6). The intrinsic factors can be physiological (newborn, older adult, overweight, pregnant, etc.), local (sweating, humidity, maceration, poor hygiene, irritations, etc.) or related 
to the patient's pathological condition (diabetes, severe malnutrition, immunosuppression especially during HIV infection or cancer, etc.) $(8,36)$. Extrinsic factors include prolonged use of corticosteroids, broad-spectrum antibiotic therapy, antiseptics, dentures, intravenous drug use, surgical procedures, organ transplantation, anticancer and cytolytic chemotherapy, radiotherapy, the use of implanted medical devices such as catheters and probes $(37,38)$.

\section{Diagnosis}

The diagnosis of candidiasis depends on the infection's location, and it is based on recognizing symptoms and taking clinical samples, direct examination, culture and identification of the germs in the sample. Serodiagnostics can also be performed.

\section{Recognition of symptoms and collection of clin- ical samples}

The clinical symptoms of Candida infection may vary depending on whether the pathogen has colonized the surface or deep tissue of the body. These symptoms may include the following: intestinal problems such as diarrhea and constipation, allergies, eating disorders, rashes, red or purple patches, white, flaky substance over affected areas, shedding of the skin with flakes, cracks in the skin, soreness, erythema, red and white lesions, endocarditis, osteoarticular involvement, and others. Laboratory diagnosis of Candida infections begins with careful collection of the appropriate clinical sample. The collection of the microbiological sample to be analyzed depends on the accessibility of the infected tissue. In the case of superficial infections, collecting clinical samples involves rubbing the lesions using a sterile swab moistened with sterile distilled water, detaching or scraping the membranous lesions using a curette, cutting nail fragments for culture, taking powder from the nail bed for direct examination, squeezing the erythematous bead of the perionyxis and collecting the serum with the swab. In the case of an invasive infection, the specimens are blood culture and biopsies. However, the anatomic site in which the organism is present must be carefully selected and the specimen collected in such a manner that it will allow the fungus to remain viable in its natural state without contamination (39).

\section{Examination by direct microscopy}

The direct examination is based on microscopic observations aimed at assessing the different fungal elements present in the clinical sample taken from the patient. For keratinized samples (dander,nails, etc.), a portion of the sample is placed on a microscope slide and clarified by adding a drop of potassium hydroxide solution ( $\mathrm{KOH}$ ) of concentration between 10 and 40\% depending on the nature of the sample (40). KOH's role is to digest the skin cells and protein debris present in the sample, thus allowing the visualization of the blastospores, budding yeast, pseudomycelium and mycelium characteristic of Candida species. The duration of $\mathrm{KOH}$ lightening depends on the nature of the sample and the concentration of $\mathrm{KOH}$ used. With $10 \% \mathrm{KOH}$, the lightening duration varies little from 20 minutes to 3 hours for dander taken from the skin. For more effective lightening, DMSO/KOH mixture can be used. Subsequently, simple staining of the preparation can be carried out to facilitate the observation of the various fungal elements. The dyes generally used are calcofluor white, Parker's ink, or the Lactophenol Cotton Blue $(41,42)$. These dyes bind to chitin, an essential component of the fungal cell wall. For body fluids such as blood and clinical samples taken from the vagina, duodenum and oropharyngeal, treatment with a keratinolytic substance such as $\mathrm{KOH}$ is generally unnecessary. The sample taken can be directly observed in the fresh state using a saline solution or even be examined in the fixed state on a slide., Simple staining or a GRAM staining can be performed on a smear to appreciate the diversity of fungal elements better in the fixed state. The dyes used in the case of a simple coloring can be Lactophenol Cotton Blue, Giemsa, or methylene blue $(39,42)$. Tissues biopsies can be stained using Gomori's methenamine silver (GMS) or periodic acid-Schiff (PAS) staining. Depending on the preparation carried out, an optical microscope or a fluorescent microscope can be used to observe the fungal structures. Specimens from exudates, sputum, urine, and cerebrospinal fluid can be viewed under a reduced-light brightfield microscope or phase-contrast microscope (43). However, the microscopic examination serves only as an indication of candidiasis without defining the etiology, which can be established only by culture (39). 


\section{Culture of clinical samples}

After taking the sample, the clinical sample is seeded on a culture medium and incubated under appropriate conditions. The seeding techniques usually used are between streaking, swabbing on agar medium or inoculation in broth. The colonies are visible after 24 to 48 hours of incubation at a temperature between 30 and $37^{\circ} \mathrm{C}$ for most Candida species. These microbial colonies will then allow the identification of the germ responsible for the infection and the determination of its sensitivity profile. Not all yeasts have the same growth requirements regarding the culture media used. Thus, basic media allows the growth of undemanding yeasts and media enriched with different substances allowing the growth of more demanding yeast species. These media are generally solid and can be differential, selective or not. In medical practice, the culture media commonly used for isolation and identification of clinical Candida species are Sabouraud Dextrose Agar (SDA), Potato Dextrose Agar (PDA), Fluoroplate candida, Yeast Potato Dextrose (YPD) agar, CHROMagar, Corn meal-Tween 80 agar and Lee's synthetic medium. Several other types of culture medium can be used depending on the objectives $(44,45)$. In the particular case of invasive candidiasis, a blood culture is recommended for diagnosis. Despite technical improvements and the use of specific media dedicated to mushrooms, the sensitivity of cultures on agar medium remains limited, around 50\%. Blood culture is generally positive in patients with active candidaemia and negative in those with deep candidiasis not associated with candidaemia. Its sensitivity is around $40 \%$ for patients with candidaemia resulting from a deep infection (46).

\section{Morphological identification}

At the end of the culture of the clinical sample taken from the patient, the identification of the germ responsible for the infection generally begins with a macroscopic observation of the microbial colonies obtained. Characteristics (the morphology, size and pigmentation of the colonies) are assessed according to the type of medium used for the culture and manufacturer's instructions. For example, on chromogenic media like the CHROMagar medium, the colonies of C. albicans are green and consistent. This macroscopic observation allows a primary identi- fication or a presumption of the microbial species at the origin of the infection. The identification of the clinical isolate is confirmed by a variety of additional tests, which begin with microscopic observation of the germ's morphological and structural characteristics. The elements most often observed are the presence and arrangement of blastoconidia, pseudohyphae, hyphae, germ tubes, and chlamydospores (47). The blastoconidia, pseudohyphae, and hyphae are observable under the microscope after achieving a fresh state, sometimes followed by a simple coloring. The microscopic description of these structures allows us to have a presumptive idea of the Candida species during characterization. For example, on Corn meal-Tween 80 agar C. albicans have elongated pseudohyphae with grape-like clusters of blastoconidia at the septa (42). Chlamydospores are present at the end of the hyphae or their short lateral branches. One of the protocols for detecting germ tubes is to seed a colony of clinical isolate in blastese broth. After 3 hours of incubation at $37^{\circ} \mathrm{C}$, a fresh state is achieved to search for characteristic germ tubes. The search for germ tubes is generally used for the identification of C. albicans. Indeed, approximately $95 \%$ of C. albicans isolates produce germ tubes, a property also shared by C. dubliniensis. Concerning chlamydospores, these structures make it possible in practice to detect and differentiate the species C. albicans and C. dubliniensis. The search for chlamydospores is carried out on a culture medium poor in nutrients such as RAT or PCB media. After culturing the germ at $25^{\circ} \mathrm{C}$ for 24 to 48 hours, large, thick-walled round spores, 10 to $15 \mu \mathrm{m}$ in diameter, associated with blastospores are formed at the terminal or lateral ends of the pseudomycelium $(48,49)$.

\section{Rapid identification tests}

Rapid identification tests generally use two methods of identification, immunological methods, and enzymatic methods. Immunological methods are based on the principle of agglutination of latex particles sensitized by monoclonal antibodies, specifically recognizing an antigen from the wall of the different species. The Bichro-latex albicans test thus identifies the C. albicans/C. dubliniensis complex. A positive reaction results in the formation of agglutinates after a few minutes. Enzymatic methods rely on detecting specific enzymes or on the ability 
of yeast to hydrolyze a given substrate. For example, the Glabrata RTT test allows the identification of C. glabrata and is based on the yeast's ability to hydrolyze trehalose and not maltose (50).

\section{Biochemical characterization}

The biochemical characterization is mainly based on the study of the sugar auxanogram, which involves assessing the clinical isolate's ability to assimilate or ferment a particular carbohydrate. These sugars can be mono or polysaccharides such as glucose, lactose, sucrose, xylose, cellobiose. (51). In practice, carbohydrate solutions are distinctly added to a culture medium devoid of carbon source. The clinical isolate is then seeded on the culture medium and incubated under defined conditions. The growth of the germ testifies to its capacity to assimilate the sugar contained in the culture medium. Another variant of the technique involves inoculating a disc paper with the sugar to be tested and then depositing it on a culture medium devoid of carbon source and previously sown with clinical isolate. The development of the germ on or around the disc testifies to its capacity to assimilate sugar. The evaluation of the carbohydrate fermentation, in general, is based on the detection of products from the fermentation pathways. These products can be acids or gases excreted in the reaction medium. These degradation products can be detected in the reaction medium using colored indicators in the case of acids, observing the turbidity of the reaction medium, or using a Durham bell in the case of gases. Nowadays, ready-to-use miniaturized techniques have been developed, such as, API 20C AUX galleries, Fungichrom, Auxacolor, Fungifast. These techniques are quick, easy to implement and allow the microbial germ to assimilate or ferment a wide variety of sugars to be assessed. Following biochemical tests, a database can be used to identify the clinical isolate according to its carbohydrate breakdown profile (52).

\section{Molecular identification}

Conventional methods for identifying Candida species are based on assimilation, fermentation reactions, and morphology (53). Since some species of Candida present few easily identifiable morphological and biochemical variations, molecular biological techniques have been developed to overcome the limitations of phenotypic identification methods. For molecular identification, several procedures have been proposed to detect and differentiate Candida species both by non-DNA-based methods and DNA based methods. The non-DNA-based methods include, for example, Multi-locus Enzyme Electrophoresis, which characterizes fungal enzymatic proteins and assesses their polymorphism (54). The DNA based methods include techniques like Electrophoretic Karyotyping, PCR, Nucleic Acid Sequence Based Amplification, DNA-microarrays, Fluorescent in situ hybridization, MLP typing, etc. $(54,55,56)$.

\section{MALDI-TOF MS method}

Matrix-assisted laser desorption ionization-time of flight mass spectrometry (MALDI-TOF MS) has been recently described as an "ongoing revolution" because it allows rapid and accurate identification of bacteria and fungi (56). In order to identify a microorganism, the peaks of the experimental spectrum acquired with MALDI-TOF MS are compared to signature peaks from reference spectra contained in databases. MALDI-TOF MS allowed rapid and accurate identification of microorganisms and became an important tool in clinical laboratories. Previous experimental studies demonstrated that MALDI-TOF MS was less arduous than routine identification methods like microscopy and biochemical tests (57). It was shown to be a reliable, fast, and straightforward method compared to conventional ones that are time-consuming and need trained professionals to be interpreted. MALDI-TOF MS also provides a promising alternative for the study of antifungal resistance $(56,57)$.

\section{Serodiagnostic}

The timely diagnosis of invasive candidiasis remains difficult as the clinical presentation is not specific and blood cultures lack sensitivity and need a long incubation time (58). Several non-culture approaches have been investigated in the search for a method to obtain an early diagnosis of invasive candidiasis. These techniques include antigen and antibody tests, DNA amplification tests, and detecting Candida metabolites in blood serum. The antigens and antibodies generally sought in the blood circulation include the mannan, $\beta$-(1,3)-D-glucan and 
anti-mannan antibodies. Mannan is a major component of the Candida cell wall, composing up to $7 \%$ of the cell dry weight, and is one of the main Candida antigens that circulate during infection. Therefore, mannan antigen and anti-mannan antibodies are present in patients with invasive candidiasis. Another important polysaccharide in the fungal wall that can be found in the bloodstream during infection is $\beta-(1,3)$-D-glucan. Mannan and $\beta-(1,3)-D$ glucan antigens can be detected in the serum using monoclonal anti-Candida antibodies, via techniques such as enzyme-linked immunosorbent assay and latex agglutination (59). Other antigens like protein from Candida blastoconidia and germ tubes can be detected in the blood by techniques such as two-dimensional electrophoresis or Western blotting. There is usually an increase in anti-Candida antibodies like anti-mannan antibodies in the blood serum during invasive candidiasis. Methods like immunoelectrophoresis and immunofluorescence can be used for the detection of these antibodies. Concerning Candida metabolites, the D-arabinitol is a metabolite of most pathogenic Candida species. Physiological concentrations of D-arabinitol in bloodplasma, CSF, and urine are in the range of 0-5 $\mathrm{Mm}$. The excess arabinitol in sera or urine of patients with invasive candidiasis is D-arabinitol. The concentration of this metabolite in the blood can be determined using gas chromatography or enzymatic analysis (60). Serological assays are used not only to detect infection but also to assess the risk of infection establishing in order to treat the patient without waiting for clinical signs.

\section{Treatment of candidiasis}

The fight against candidiasis is based on the adoption of preventive measures aimed at preventing the spread of infection and the use of antifungals. Historically, amphotericin B has long been used as the sole drug against fungal infections and candidiasis in particular. Over time, better knowledge of the structure and metabolism of pathogenic fungi has made it possible to develop other antifungal agents with different targets, and the therapeutic offer has gradually diversified (61). Nowadays, commercially available antifungals are in various dosage forms, and their use depends on the nature and location of the infection (Table 2). Thus, skin or genital infections are treated with the local application of antifungal agents in the form of creams, ointments, solutions or ova; however, deep or visceral candidiasis is mostly treated with intravenous antifungals. The antifungal molecules currently used in drug design can be grouped into four main groups: polyenes, fluoropyrimidines, azoles and echinocandins (62).

\section{Polyenes}

Polyenes (nystatin, amphotericin B, natamycin, etc.) are amphoteric macrocyclic lactones characterized by a lipophilic apolar part having several conjugated double bonds and a polar part comprising many hydroxyl groups. Their main target is ergosterol, the essential component of the yeast plasma membrane (61). Their binding to ergosterol creates pores at the level of the fungal membrane, increasing its permeability. Compounds essential to the life of yeast ( $\mathrm{K}+$ ions, etc.) diffuse out of the cytosol, and this leads to the death of the pathogen (63). This affinity for ergosterol is most often the cause of their toxicity in humans. Indeed, polyenes such as amphotericin B and nystatin have a significant affinity for cholesterol, the equivalent in humans of fungal ergosterol. Also, polyenes are poorly resorbed amphiphilic molecules, which is causing their toxicity (64).

\section{Fluoropyrimidines}

The only representative of this family used in the treatment of candidiasis is 5-fluorocytosine (5-FC), a structural analogue of cytosine (62). It is a prodrug that is first converted to 5 -fluorouracil (5-FU) inside the fungal cell by cytosine deaminase, which gives it its fungistatic power. The toxic 5-FU exerts its antimetabolic action in two ways. It can first be converted into 5-fluorodeoxyuridine monophosphate, which inhibits thymidylate synthetase, an enzyme necessary for the synthesis of DNA. It can also be converted to 5 -fluorouridine triphosphate, a compound that incorporates mRNA in place of uridine, thereby inhibiting protein synthesis $(67,68)$. These molecules are of limited indication because they can cause the rapid emergence of resistant mutants under monotherapy. It is essential to use 5-FC in combination to avoid the selection of resistant mutants. In some patients, it can cause leukopenia, agranulocytosis, cytolysis, or gastric pain (69). 
Table 2. Some antifungals used in the treatment of invasive and superficial candidiasis $(53,61)$

\begin{tabular}{|c|c|c|}
\hline Disorder & Drug & Dosage and administration route \\
\hline \multirow{12}{*}{ Invasive candidiasis } & 5-fluorocytosine & $100-200 \mathrm{mg} / \mathrm{kg}$ per day (Oral or i.v.) \\
\hline & Amphotericin B deoxycholate & 0.7 to $1 \mathrm{mg} / \mathrm{kg}$ per day (i.v.) \\
\hline & Amphotericin B lipid complex & $5 \mathrm{mg} / \mathrm{kg}$ per day (i.v.) \\
\hline & Anidulafungine & $200 \mathrm{mg}$ the first day then $100 \mathrm{mg} /$ day as a curative (i.v.) \\
\hline & Caspofungine & $70 \mathrm{mg} / \mathrm{kg}$ then $50 \mathrm{mg} / \mathrm{kg}$ (i.v.) \\
\hline & Fluconazole & $800 \mathrm{mg}$ the first day then 200 to $400 \mathrm{mg} /$ day (Oral or i.v.) \\
\hline & Itraconazole & 200-1200 mg/day; Oral \\
\hline & Ketoconazole & $200-400 \mathrm{mg} /$ day (Oral) \\
\hline & Liposomal amphotericin B & $3 \mathrm{mg} / \mathrm{kg}$ per day (i.v.) \\
\hline & Micafungine & $100-200 \mathrm{mg} /$ day (2-4 mg/kg per day) as curative (i.v.) \\
\hline & Posaconazole & $400 \mathrm{mg} \times 2 /$ day as curative (or $200 \mathrm{mg} \times 4 /$ day) (Oral) \\
\hline & Voriconazole & $\begin{array}{l}2 \times 400 \mathrm{mg} \text { (or } 2 \times 6 \mathrm{mg} / \mathrm{kg} \text { ) on the first day then } 2 \times 200 \mathrm{mg} / \text { day } \\
\text { (or } 2 \times 4 \mathrm{mg} / \mathrm{kg} \text { ) (Oral or i.v.) }\end{array}$ \\
\hline \multirow{3}{*}{$\begin{array}{l}\text { Chronic mucocutaneous } \\
\text { candidosis }\end{array}$} & Fluconazole & $50-400 \mathrm{mg} /$ day \\
\hline & Itraconazole & $100-400$ mg/day \\
\hline & Posaconazole & $100-400$ mg/day \\
\hline \multirow{8}{*}{ Oesophagitis } & Anidulafungin & 100 mg/day \\
\hline & Caspofungin & $50 \mathrm{mg} /$ day \\
\hline & D-AMB & $0.5-0.7 \mathrm{mg} / \mathrm{kg} /$ day (i.v.) \\
\hline & Fluconazole & $200-400$ mg/day \\
\hline & Itraconazole & $2 \times 200 \mathrm{mg} /$ day (oral) \\
\hline & L-AMB & $1-3 \mathrm{mg} / \mathrm{kg} /$ day (i.v.) \\
\hline & Micafungin & 150 mg/day \\
\hline & Voriconazole & $400 \mathrm{mg} /$ day \\
\hline \multirow{5}{*}{$\begin{array}{l}\text { Oropharyngeal candidosis } \\
\text { and Laryngitis }\end{array}$} & Amphotericin B & 0.5 (to 2.4) g/day (oral) \\
\hline & Fluconazole & $50-200 \mathrm{mg} /$ day \\
\hline & Itraconazole & $100-200 \mathrm{mg} /$ day (oral) \\
\hline & Nystatin & $6 \times 100,000$ units/day (oral) \\
\hline & Posaconazole & 100 mg/day \\
\hline \multirow{2}{*}{ Skin/nails infections } & Fluconazole & $50-200 \mathrm{mg} /$ day \\
\hline & Itraconazole & $100-200$ mg/day \\
\hline \multirow{2}{*}{ Vaginal candidosis } & Clotrimazole & - \\
\hline & Fluconazole & $150 \mathrm{mg} / \mathrm{day}$ \\
\hline
\end{tabular}




\section{Azoles}

Azole derivatives are the most used antifungals in the treatment of candidiasis. They are grouped into two subfamilies, imidazoles (ketoconazole, miconazole, etc.) and triazoles (fluconazole, itraconazole, etc.). They have a fungistatic action, and their main target is the pathway of ergosterol biosynthesis. By blocking the expression of the Erg11 gene, which codes for $14 \alpha$-lanosterol demethylase, responsible for the transformation of lanosterol into ergosterol, azoles cause an accumulation of toxic methyl sterols and an alteration of the cell membrane of the pathogen (70). Despite their clinical efficacy, many side effects have been reported following their use. These side effects include acute heart failure, neuropathy, dependent IgE hypersensitivity, digestive disorders and inflammatory skin reactions $(71,72)$.

\section{Echinocandins}

Echinocandins (caspofungin, micafungin, anidulafungin, etc.) are synthetic derivatives of lipopeptides. They inhibit $\beta$-(1,3)-D-glucan synthetase, the enzyme responsible for the synthesis of $\beta$ - $(1,3)-D$ glucan, one of the structural components involved in maintaining the integrity and the rigidity of the wall. The weakening of the wall, which results in a leak of intracellular material, causes lysis of the fungal cell (73). The good tolerance of echinocan- dins and their spectrum of action place them the first-line treatment of systemic candidiasis (74). However, there is increasing resistance of microbial strains to these antifungals (75).

\section{CONCLUSION}

Because of the resurgence of diseases and treatments weakening the immune system, candidiasis is nowadays a real public health problem and regularly mentioned as co-infection in clinical settings. Several species of Candida are the cause of these infections, and Candida albicans remains the most involved species. Candida infections can range from superficial to systemic, and several diagnostic methods have been described. Methods commonly used in the identification of clinical isolates include, among others, morphological culture tests, differential agar media, and biochemical assimilation tests. However, for more efficient identification of the Candida isolates causing the infection, molecular or immunological identification techniques have been developed. The diagnosis, the identification of the Candida species at the origin of the infection, and the choice of the most effective antifungal are essential for better patient management. This review is a contribution to the management of Candida infections.
Peer-review: Externally peer-reviewed

Conflict of Interest: The author have no conflict of interest to declare.
Financial Disclosure: The authors declared that this study has received no financial support.

\section{REFERENCES}

1 Bongomin F, Gago S, Oladele R, Denning D. Global and Multi-National Prevalence of Fungal Diseases-Estimate Precision. J Fungi (Basel) 2017; 3: 57.

2 Gupta P, Gautam P, Rai N, Kumar N. An emerging hope to combat Candida albicans: plantbased therapeutics. Biotechnol Int 2012; 5: 85-114

3 Calderone RA, Clancy CJ, editors. Candida and Candidiasis. Washington: American Society of Microbiology Press. 2012.

4 Hani U, Hosakote G, Vaghela R, Osmani RA, Shrivastava A. Candidiasis: a fungal infection-current challenges and progress in prevention and treatment. Infect Disord Drug Targets
2015; 15: 42-52

5 Berkow EL, Lockhart SR. Fluconazole resistance in Candida species: a current perspective. Infect Drug Resist 2017; 10: 237-45.

6 Han Y, Ulrich M, Cutler J. Candida albicans mannan extract-protein conjugates induce a protective immune response against experimental candidiasis. J Infect Dis 1999; 179: 1477-84.

7 Cateau E, Rodier MH, Imbert C. Candidoses associées aux cathéters : Quelle place pour les verrous antifongiques? [Could antifungal lock be useful in the management of candiasis linked with catheters ?] Med Sci (Paris) 2012; 28: 740-5.

8 Madhu P. Oral candidiasis. Int J Pharm Sci Invent 2013; 2 : 3-6. 
9 Guessous-Idrissi N, Essari A, Abdallaoui S, Youssouf M Première identification de Candida dubliniensis au centre hospitalier universitaire Ibn Rochd de Casablanca, Maroc. J Mycol Med 2007; 17: 77-81.

10 Eggimann P, Que YA, Revelly J P, Pagani JL. Preventing invasive Candida infections. Where could we do better? J Hosp Infect 2015; 89: 302-8.

11 Seleem D, Pardi V, Mendonça Murata R. Review of flavonoids: a diverse group of natural compounds with anti-Candida albicans activity in vitro. Arch Oral Biol 2017; 76: 76-83.

12 Allen CM, Saffer A, Meister RK, Beck FM, Bradway S. Compar ison of a lesion-inducing isolate and a nonlesional isolate of Candida albicans in an immunosuppressed rat model of oral candidiasis. J Oral Pathol Med 1994; 23: 133-9.

13 McIlroy M. Failure of fluconazole to suppress fungemia in a patient with fever, neutropenia and typhlitis. J Infect Dis 1991; 163: 420-1.

14 Marinho S, Teixeira AB, Santos OS, Cazanova RF, Ferreira CA, Cherubini K, de Oliveira SD. Identification of Candida spp. by phenotypic tests and PCR. Braz J Microbiol 2010; 41: 286-294.

15 Godoy P, Almeida LP, Lopes-Colombo A. Identificación de Candida albicans utilizando el medio cromogénico Albicans ID. Rev Iberoam Micol 2001; 18: 197-9.

16 Lortholary O, Desnos-Oliver M, Sitbon K, Fontanet A, Bretagne $\mathrm{S}$, Dromer F, et al. Recent exposure to caspofungin or fluconazole influences the epidemiology of candidemia: a prospective multicenter study involving 2,441 patients. Antimicrob Agents Chemother 2011; 55: 532-8.

17 Sanguinetti M, Posteraro B, Lass-Flörl C. Antifungal drug resistance among Candida species: mechanisms and clinical impact. Mycoses 2015; 58: 2-13.

18 Céline Lagane. Rôle de l'IL-13 et des ligands de PPAR- $\gamma$ dans la réponse anti-infectieuse des macrophages murins et des monocytes humains vis-a-vis de Candida albicans. Implication de PPAR- $\gamma$. Université de Toulouse, PhD thesis, 2007.

19 Fitzpatrick D, Logue M, Stajich JE, Butler G. A fungal phylogeny based on 42 complete genomes derived from supertree and combined gene analysis. BMC Evol Biol. 2006; 6: 92-9.

20 Develoux M, Bretagne S. Candidoses et levuroses diverses. EMC Mal Infect 2005; 2: 119-39.

21 Kah N. Dermatophyties, candidoses et autres mycoses superficielles: rôles du pharmacien d'officine. Université Henri Poincaré-Nancy, PhD thesis, 2011.

22 El-Kirat-Chatel S. Développement d'outils cellulaires et moléculaires pour l'étude des interactions Candida - phagocytes ; Application à la caractérisation du gène OLE2 codant une désaturase chez C. lusitaniae. Université Victor Segalen Bordeaux 2, PhD thesis, 2010

23 Mayer FL, Wilson D, Hube B. Candida albicans pathogenicity mechanisms. Virulence. 2013; 4: 119-28.

24 Buffaz C, Hodille E, Jourdy Y, Louvrier C, Marijon A. Parasitologie et mycologie médicale pratique. Edition De boeck Supérieur; 2014. p. 180-8

25 Coronado-Castellote L, Jiménez-Soriano Y. Clinical and micro- biological diagnosis of oral candidiasis. J Clin Exp Dent 2013; 5: 279-86.

26 Erdogan A, Rao SS. Small intestinal fungal overgrowth. Curr Gastroenterol Rep 2015; 17: 1-16.

27 Samaranayake LP, Fidel PL, Naglik JR, Sweet SP, Teanpaisan R, Coogan MM, et al. Fungal infections associated with HIV infection. Oral Dis 2002; 8: 151-60.

28 Ryan KJ, Ray CG, Sherris JC. Candida, Aspergillus and Other Opportunistic Fungi. Ryan KJ, Ray CG, editors. Sherris Medical Microbiology. London: McGraw-Hill; 2004. p. 659-68.

29 O'Farrell N, Quigley M, Fox P. Association between the intact foreskin and inferior standards of male genital hygiene behaviour: a cross-sectional study. Int J STD AIDS 2005; 16: 556-9.

30 Estupiñan BA, Sandhu N. Chronic Mucocutaneous Candidiasis. Medscape/eMedicine 2017 Apr. Available from: URL: https:// emedicine.medscape.com/article/1091928-differential

31 Metin A, Dilek N, Bilgili S. Recurrent candidal intertrigo: challenges and solutions. Clin Cosmet Investig Dermatol 2018; 11: 175-85.

32 Rodgers P, Bassler M. Treating Onychomycosis. Am Fam Physician. 2001; 63: 663-673.

33 Pfaller M, Diekema DJ. Epidemiology of invasive candidiasis: a persistent public health problem. Clin Microbiol Rew 2007; 20: 133-63.

34 Diekema D, Arbefeville S, Boyken L, Kroeger J, Pfaller M. The changing epidemiology of healthcare-associated candidemia over three decades. Diagn Microbiol Infect Dis 2012; 73: 45-8.

35 Uppuluri P, Chaturvedi AK, Srinivasan A, Banerjee M, Ramasubramaniam AK, Köhler JR, et al. Dispersion as an important step in the Candida albicans biofilm developmental cycle. PLoS Pathog 2010; 6: 1-12.

36 Talarmin JP, Boutoille D, Tattevin P, Dargère S, Weinbreck P, Ansart S, et al. Epidémiologie des candidémies: étude observationnelle prospective d'un an dans l'Ouest de la France. Med Mal Infect 2009; 39: 877-85.

37 Zaoutis TE, Argon J, Chu J, Berlin JA, Walsh TJ, Feudtner C. The epidemiology and attributable outcomes of candidemia in adults and children hospitalized in the United States: a propensity analysis. Clin Infect Dis 2005; 41: 1232-9.

38 Cateau E, Rodier MH, Imbert C. Candidoses associées aux cathéters: Quelle place pour les verrous antifongiques? Med Sci (Paris). 2012; 28: 740-5.

39 Arvind Babu R, Reddy B, Anuradha C, Chandrasekar P. Handbook for microbiology practice in oral and maxillofacial diagnosis. A study guide to laboratory techniques in oral microbiology. Bloomington: iUniverse; 2015

40 Neppelenbroek KH, Seó RS, Urban VM, Silva S, Dovigo LN, Jorge $\mathrm{JH}$, et al. Identification of Candida species in the clinical laboratory: a review of conventional, commercial, and molecular techniques. Oral Dis 2014; 20: 329-44.

41 Sachin CD, Santosh S. Laboratory approach for diagnosis of candidiasis through ages Int J Curr Microbiol App Sci 2014; 3 : 206-18.

42 Deorukhkar SC, Roushani S. Identification of Candida Species: 
Conventional Methods in the Era of Molecular Diagnosis. Ann Microbiol Immuol 2018; 1: 1-6.

43 Aslanzadeh J, Roberts G. Direct microscopic examination of clinical specimens for the laboratory diagnosis of fungal infections. Clin Microbiol Newsl 1991; 13: 185-92.

44 Jatta B, Gunasekaran M, Mohan N. Influence of cultural conditions on lipase production in Candida albicans. Asian J Biotechnol 2009; 1: 118-23.

45 Madhavan P, Jamal F, Chong PP. Laboratory isolation and identification of Candida species. J Appl Sci 2011; 11: 2870-7.

46 Clancy CJ, Nguyen MH. Non-culture diagnostics for invasive candidiasis: promise and unintended consequences. J Fungi 2018; 4: 27.

47 Pincus DH, Orenga S, Chatellier S. Yeast identification-past, present, and future methods. Med Mycol 2007; 45: 97-121.

48 Larone DH. Medically important fungi: a guide to identification. London: Harper and Row; 1976.

49 Sullivan DJ, Moran G, Donnelly S, Gee S, Pinjon E, McCartan B, et al. Candida dubliniensis: An update. Rev Iberoam Micol 1999; 16: 72-6.

50 Pianetti C. Place du sérodiagnostic dans les infections fongiques invasives à Candida. Enquête sur la prescription des sérologies Candida au CHU de Nancy et comparaison de deux kits commerciaux ELISA pour la détection des antigènes mannanes et anticorps anti-mannanes. University of Lorraine, Master's thesis, 2015.

51 Koneman EW, Allen SD, Janda WM, Schreckenberger PC, Winn WC. Color Atlas and Textbook of Diagnostic Microbiology. 4th ed. Philadelphia: Lippincott; 1992. p. 791-878.

52 Segal E, Elad D. Candidiasis. In Topley and Wilson s Medical Mycology. 10th ed. Edward Arnold Publishers; 2005. p. 579-623.

53 Cirak MY, Kalkanci A, Kustimur S. Use of molecular methods in identification of Candida Species and evaluation of fluconazole resistance. Mem Inst Oswaldo Cruz 2003; 98: 1027-32.

54 Sudhan SS, Sharma P, Sharma M, Shrivastava D. Identification of Candida species in the clinical laboratory: a review of conventional, commercial and molecular techniques. Int J Med Res Prof 2016; 2: 1-8.

55 Shepard JR, Addison RM, Alexander BD, Della-Latta P, Gherna M, Haase G, et al. Multicenter evaluation of the Candida albicans/Candida glabrata peptide nucleic acid fluorescent in situ hybridization method for simultaneous dual-color identification of C. albicans and C. glabrata directly from blood culture bottles. J Clin Microbiol 2008; 46: 50-5.

56 Yaman G, Akyar I, Can S. Evaluation of the MALDI TOF-MS method for identification of Candida strains isolated from blood cultures. Diagn Microbiol Infect Dis 2012; 73: 65-7.

57 Delavy M, Dos Santos AR, Heiman CM, Coste AT. Investigating antifungal susceptibility in Candida species with MALDI-TOF MS-based assays. Front Cell Infect Microbiol 2019; 9: 19.

58 Mikulska M, Calandra T, Sanguinetti M, Poulain D, Viscoli C; Third European Conference on Infections in Leukemia Group. The use of mannan antigen and anti-mannan antibodies in the diagnosis of invasive candidiasis: recommendations from the Third European Conference on Infections in Leukemia. Crit Care 2010; 14: R222.

59 Bretagne S. Antigènes fongiques en réanimation : tests disponibles et état des lieux. Réanimation. 2007; 16: 232-9.

60 Christensson B, Sigmundsdottir G, Larsson L. D-Arabinitol- a marker for invasive candidiasis. Med Mycol 1999; 37: 391-6.

61 Robert-Gangneux F, Chevrier S, Guiguen C. Les antifongiques disponibles pour le traitement des mycoses systémiques et cutanées profondes. Médecine Thérapeutique 2010; 16: 313-28.

62 Vandeputte P. Mécanismes moléculaires de la résistance aux antifongiques chez Candida glabrata. University of Angers, PhD thesis, 2008.

63 Bellet V. Mécanismes de résistance aux Anifongiques. Laboratoire de Parasitologie et mycologie médicale, Faculté de Pharmacie, 2017.

64 Adamczyk E. Les antifongiques en médecine vétérinaire. University of Claude-Bernard, PhD thesis, 2011.

65 Lemke A, Kiderlen A, Kayser O. Amphotericin B Appl Microbial Biot 2005; 68: 151-62.

66 Van Bambeke F. Cours sur les antifongiques. Antifongiques. 2011-2012; 1-17.

67 Accoceberry I, Noël T. Antifongiques: cibles cellulaires et mécanismes de résistance [Antifungals cellular targets and mechanisms of resistance]. Therapie. 2006; 61: 195-9.

68 Papon N, Noël T, Florent M, Gibot-Leclerc S, Jean D, Chastin C, et al. Molecular mechanism of flucytosine resistance in Candida lusitaniae: contribution of the FCY2, FCY1, and FUR1 genes to 5-fluorouracil and fluconazole cross-resistance. Antimicrob Agents Chemother 2007; 51: 369-71.

69 Vermes A, Guchelaar HJ, Dankert J. Flucytosine: a review of its pharmacology, clinical indications, pharmacokinetics, toxicity and drugs interactions. J Antimicrob Chemother 2000; 46: 171-9.

70 Sanglard D, Ischer F, Parkinson T, Falconer D, Bille J. Candida albicans mutations in the ergosterol biosynthetic pathway and resistance to several antifungal agents. Antimicrob Agents Chemother 2003; 47: 2404-12.

71 Carballeira NM. New advances in fatty acids as antimalarial, antimycobacterial and antifungal agents. Prog Lipid Res 2008; 47: 50-61.

72 Paleiron N, Bizien N, Vinsonneau U, Andre M, Grassin F. Insuffisance cardiaque aiguë sous itraconazole: une complication prévisible? [Acute cardiac failure due to itraconazole] Rev Mal Respir 2011; 28: 352-4.

73 Stone EA, Fung HB, Kirschenbaum HL. Caspofungin: an echinocandin antifungal agent. Clin Ther 2002; 24: 351-77.

74 Pappas PG, Kauffman CA, Andes D, Benjamin DK, Calandra TF, Edwards JE, et al. Clinical practice guidelines for the management of candidasis: 2009 update of the infectious disease society of America. Clin Infect Dis 2009; 48: 503-35.

75 Pfeiffer CD, Garcia-Effron G, Zaas AK, Perfect JR, Perlin DS, Alexander BD. Breakthrough invasive candidiasis in patients on micafungin. J Clin Microbiol 2010; 48: 2373-80. 